\title{
Safety of Ramucirumab Regimen Without H1-antihistamine Premedication in Patients With Solid Cancers
}

\author{
EMI GOTO ${ }^{1,2}$, TOSHIFUMI YAMAGUCHI ${ }^{3,4 *}$, NOBUHIRO HATTORI ${ }^{3,5}$, MASAHIRO GOTO $^{3}$, \\ MASAMI NISHIHARA ${ }^{1}$, KAZUHISA UCHIYAMA ${ }^{1}$ and YOSHIYUKI RIKITAKE ${ }^{2}$ \\ ${ }^{1}$ Department of Pharmacy, Osaka Medical College Hospital, Takatsuki, Japan; \\ ${ }^{2}$ Laboratory of Medical Pharmaceutics, Kobe Pharmaceutical University, Kobe, Japan; \\ ${ }^{3}$ Cancer Chemotherapy Center, Osaka Medical College, Takatsuki, Japan; \\ ${ }^{4}$ Department of Frontier Science for Cancer and Chemotherapy, \\ Osaka University Graduate School of Medicine, Suita, Japan; \\ ${ }^{5}$ Department of Gastroenterology, Hirakata Municipal Hospital, Hirakata, Japan
}

\begin{abstract}
Background/Aim: To prevent infusion-related reactions (IRRs), HI-antihistamines $\left(H_{1} A T\right)$ are recommended as a premedication for monoclonal antibodies, such as Ramucirumab (RAM), even though there are $H_{1} A T$-related side effects, such as drowsiness and dizziness. Here, we investigated the safety of $H_{1} A T$-free $R A M$ regimens in patients with solid cancer. Patients and Methods: We retrospectively reviewed the patients with solid cancer receiving RAM without $H_{1} A T$ at Osaka Medical College Hospital between 2015 and 2019. Results: Among the 123 registered patients, 58 were identified as eligible. The total number of RAM infusions was 291, and the median number of RAM administration was 4 cycles (range $=1-23$ cycles). IRRs were not observed in any patient. Conclusion: Although our data are preliminary and limited, $H_{1} A T$-free $R A M$ regimens may be a treatment option for cancer patients having a significant risk of developing $H_{1}$ AT-related side effects. Further studies are needed to confirm the safety of $H_{1} A T$-free $R A M$ regimens.
\end{abstract}

Monoclonal antibodies (mAbs) have been widely used for the treatment of various malignancies (1-3). As most mAbs show lower toxicity than conventional anticancer agents, they are generally better tolerated (2-4). However, like other infused

This article is freely accessible online.

Correspondence to: Toshifumi Yamaguchi, Department of Frontier Science for Cancer and Chemotherapy, Osaka University Graduate School of Medicine, 2 Chome-2 Yamadaoka, Suita, Osaka 565-0871, Japan. Tel: +81 668792641, Fax: +81 668792639, e-mail: yamagu.toshifumi@gmail.com

Key Words: Ramucirumab, infusion-related reactions, H1antihistamines, monoclonal antibodies. anticancer agents, mAbs may cause infusion-related reactions (IRRs) (1-3). Most IRRs are mild with symptoms such as chills, fever, nausea, skin rash, and pruritus. Although severe side effects are less frequent, they may be fatal without appropriate intervention care. The incidence of IRRs varies by agent, mostly during the first or second infusion (4-6). Although the exact etiology of IRRs remains unclear, they may arise via either immunoglobulin $\mathrm{E}$ ( $\mathrm{IgE}$ )-dependent or independent mechanisms. The mAbs interact with their molecular targets on circulating blood cells, tumor cells, or effector cells recruited to the tumor site, thereby promoting the release of inflammatory cytokines $(6,7)$. When released into the circulation, cytokines can produce a wide range of symptoms, characteristic of IRRs. Premedication with H1antihistamines $\left(\mathrm{H}_{1} \mathrm{AT}\right)$, acetaminophen, or corticosteroids is a common practice to prevent IRRs associated to mAb use $(1,5)$. It is difficult to evaluate adverse events, such as IRRs, through prospective studies due to the unexpected nature of these events. In a previous observational study, the rate of IRRs did not change with dexamethasone (DEX) reduction as a premedication in cetuximab treatment (8). The underlying nature of IRRs needs to be characterized in order to identify patients at risk, as well as provide optimal prophylactic measures and symptom management.

Ramucirumab (RAM) is a fully human mAb (IgG1) directed against the vascular endothelial growth factor receptor 2 (VEGFR2), developed for the treatment of solid cancers (9). IRRs occur in $1 \%-7 \%$ of patients who receive RAM, and high-grade (Grade 3 and 4) reactions occur in $<1 \%$ of patients (9-14). Although IRRs are rarely observed in clinical practice during RAM infusions, $\mathrm{H}_{1} \mathrm{AT}$ premedication is still recommended to reduce the risk of IRRs during RAM treatment. In fact, as stated in the package insert of RAM in the United States, $\mathrm{H}_{1}$ AT are recommended as the sole anti-allergy prophylactic premedication to treat 


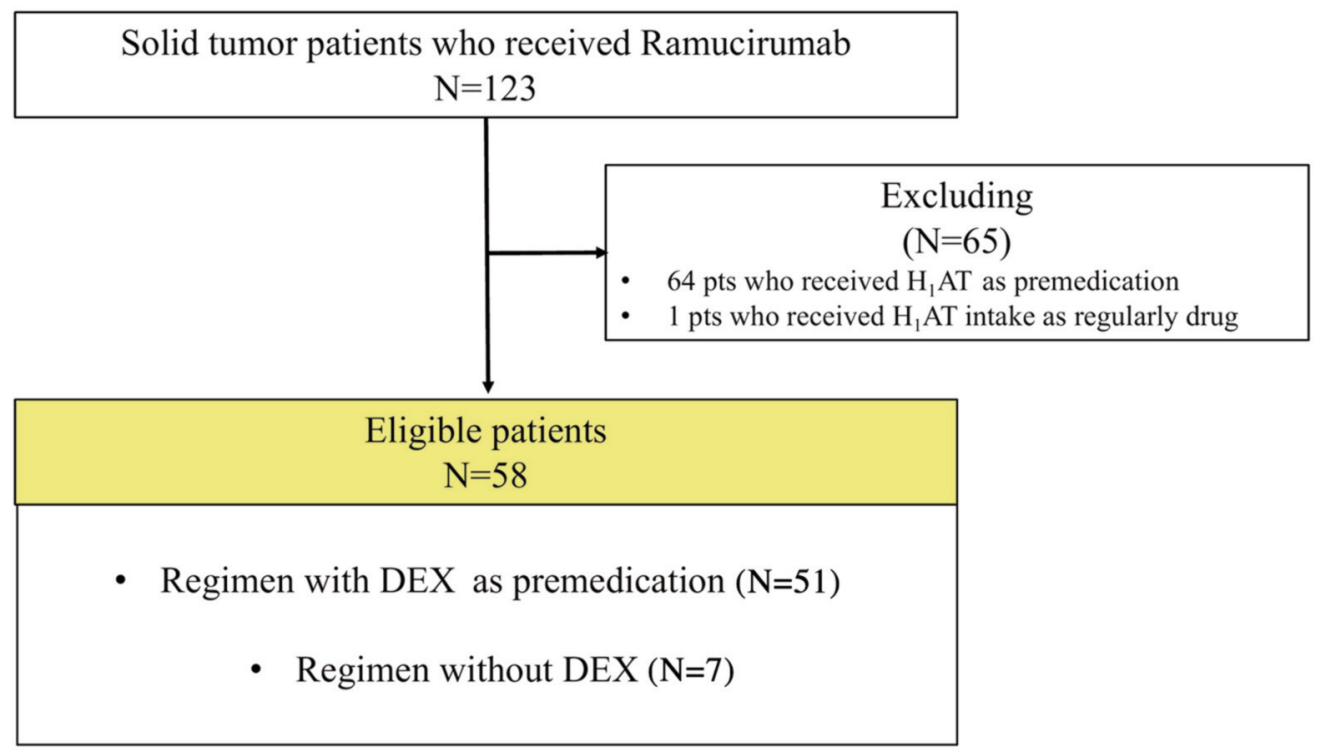

Figure 1. CONSORT diagram. H1AT: H1-antihistamine; DEX: dexamethasone.

IRRs caused by RAM. However, $\mathrm{H}_{1}$ AT may cause several side effects, including drowsiness and dizziness (15), and therefore, their use should be carefully administered in the elderly and those who need to drive. To date, it is unclear whether $\mathrm{H}_{1}$ AT-free RAM regimens can be considered safe for the patients with cancer. Therefore, our aim was to investigate the safety of $\mathrm{H}_{1} \mathrm{AT}$-free $\mathrm{RAM}$ regimens in patients with solid cancers.

\section{Patients and Methods}

Study subjects. We retrospectively reviewed the patients with solid cancer who received RAM-containing regimens with or without $\mathrm{H}_{1} \mathrm{AT}$ at the Osaka Medical College Hospital from June 1, 2015 to July 7, 2019. We selected patients who met the following four inclusion criteria: i) being $>20$ years old, ii) Eastern Cooperative Oncology Group (ECOG) performance status (PS) of 0 to 2, iii) having histologically confirmed cancers, and iv) receiving RAM without $\mathrm{H}_{1} \mathrm{AT}$. The exclusion criterion was having daily use of $\mathrm{H}_{1} \mathrm{AT}$ due to allergic diseases. Antiemetic steroids for cytotoxic chemotherapy were acceptable.

Evaluation. The incidence of IRRs during the infusions within the first cycle and the total number of cycles, as well as the incidence of other adverse events (allergic and RAM-related) was investigated according to the Common Terminology Criteria for Adverse Events (CTCAE), version 5.0. Each chemotherapy regimen, including dose and duration, was determined by the corresponding physician. Generally, patients received intravenous RAM $(8 \mathrm{mg} / \mathrm{kg})$ for 1 hour every 7 or 14 days with or without other chemotherapeutics.

Data analysis. Bivariate analyses, chi-square tests, or Fisher's exact probability tests were used to evaluate the significance of incidence of IRRs. All data were analyzed using JMP ${ }^{\circledR} 14$ (SAS Institute Inc., Cary, NC, USA), and $p<0.05$ was considered statistically significant.

\section{Results}

Patient characteristics. Out of 123 registered patients, 58 were identified as eligible subjects for this retrospective study (Figure 1). Fifty-one patients received RAM with DEX as premedication and 7 patients did not have DEX. Patient characteristics are listed in Table I. Median age was 72 (range $=39-83$ ) years old, 58\% were male, 26\% had a history of allergies, and patients who had lung cancer, gastric cancer, and colorectal cancer were $48.4 \%, 44.8 \%$, and $6.9 \%$, respectively.

Incidence of IRRs and premedication. Regimens were categorized into Groups A-E, according to the combination and doses of DEX. Premedication in regimens A, B, D, and $\mathrm{E}$ was $6.6 \mathrm{mg}$ of $\mathrm{DEX}$, while regimen $\mathrm{C}$ had no premedication (Table II). The total number of RAM infusions was 291. Moreover, the median cycle number per patient was 4 (range $=1-23$ cycles), and the median dosage of RAM for all patients was $470 \mathrm{mg}$ (range $=164-892 \mathrm{mg}$ ). The overall incidence of IRRs was 0\% (0/291) (Table III).

Other adverse events. Toxicities associated with an initial treatment are listed in Table IV. Although there were no IRRs, other RAM-related adverse events did occur. Proteinuria and hypertension were experienced by $32.8 \%$ and $13.8 \%$ of the patients, respectively. Severe toxicities of grade 3 or 4 included proteinuria $(6.9 \%)$, hypertension $(1.7 \%)$ and bleeding $(1.7 \%)$. 
Table I. Patient characteristics.

\begin{tabular}{lc}
\hline Criteria & $\mathrm{N}=58(\%)$ \\
\hline Age median (range) & $72(39-83)$ \\
Gender & $34(58.6)$ \\
Male & $24(41.4)$ \\
Female & \\
Origin & $28(48.3)$ \\
Lung cancer & $26(44.8)$ \\
Gastric cancer & $4(6.9)$ \\
Colon cancer & \\
PS & $20(34.5)$ \\
0 & $38(65.5)$ \\
1 & \\
History of allergies & $11(20.1)$ \\
Medicine & $2(3.4)$ \\
Food & $2(3.4)$ \\
Food \& medicine & $43(73.1)$ \\
Not applicable & \\
Daily medicine & $5(8.6)$ \\
Steroids & $53(91.4)$ \\
Not applicable & \\
\hline
\end{tabular}

PS: Performance status.

\section{Discussion}

The present study investigated the safety of $\mathrm{H}_{1}$ AT-free RAM regimens in patients with solid cancers. On evaluating these regimens, we found that none of the patients receiving $\mathrm{H}_{1}$ ATfree RAM-containing regimens experienced IRRs.

These results are in conflict compared to RAM-induced IRRs in patients with solid cancer identified in the RAINBOW (5.8\%) (10), REGARD (0.4\%) (11), REVEL (3.7\%) (12), REACH (6.1\%) (13), REACH-2 (6.6\%) (14) and RAISE (5.9\%) (9) trials (Table V). The regimens for gastrointestinal cancer patients used in the RAINBOW (10) and RAISE (9) trials consisted of RAM combination therapy with cytotoxic drugs, and DEX as premedication. However, it is unclear whether $\mathrm{H}_{1} \mathrm{AT}$ was used for the prevention of IRRs. The RAISE trial regimen consisted in RAM monotherapy without DEX, and only $57.8 \%$ of the patients received $\mathrm{H}_{1} \mathrm{AT}$ (9). Although DEX was not used as premedication, the incidence of IRRs in the REGARD trial was lower than in the RAINBOW and RAISE trials. DEX and $\mathrm{H}_{1} \mathrm{AT}$ are generally used as anti-allergy premedication $(1,5)$. However, the benefits of these drug combination are unknown, and suitable doses are not well established. In clinical practice, DEX and $\mathrm{H}_{1} \mathrm{AT}$ are considered beneficial to reduce the occurrence of RAM-induced IRRs. Considering the rate of incidence of IRRs in the RAINBOW (5.8\%) and RAISE (5.9\%) trials, DEX and $\mathrm{H}_{1}$ AT premedication is likely to reduce the risk of IRRs. In contrast, although the use of $\mathrm{H}_{1}$ AT premedication was only 57.8\% in the REGARD trial, IRRs were rarely observed.
Table II. Treatment regimens, premedication, and total infusion.

\begin{tabular}{lccc}
\hline Regimen & N (\%) & Premedication & Total infusion \\
\hline A: Docetaxel+RAM & $28(47)$ & DEX 6.6 mg & 139 \\
B: Nab-Paclitaxel+RAM & $18(31)$ & DEX 6.6 mg & 81 \\
C: RAM monotherapy & $7(12)$ & - & 29 \\
D: FOLFIRI+RAM & $4(8)$ & DEX 6.6 mg & 35 \\
E: Irinotecan+RAM & $1(2)$ & DEX 6.6 mg & 7 \\
\hline
\end{tabular}

RAM: Ramucirumab; FOLFIRI: leucovorin calcium; 5-fluorouracil, and irinotecan; DEX: dexamethasone.

Table III. Incidence of infusion-related reactions in H1AT-free ramucirumab regimens.

\begin{tabular}{lc}
\hline Factors & Results \\
\hline Total number of ramucirumab infusions & 291 \\
Number of cycles per patient, median (range) & $4(1-23)$ \\
Ramucirumab dosage, median (range), mg/kg & $470(164-892)$ \\
Incidence of IRRs at first cycle, \% (95\%CI) & $0(0-0.06)$ \\
Incidence of IRRs at all cycles, \% (95\%CI) & $0(0-0.07)$
\end{tabular}

$\mathrm{H}_{1} \mathrm{AT}$ : H1-antihistamines; $\mathrm{CI}$ : confidence interval.

Using molecular targeting agents, the MABEL trial (16) has reported that the incidence of IRRs using cetuximab (chimeric mouse-human mAbs) was higher in colorectal cancer patients who received $\mathrm{H}_{1} \mathrm{AT}$ alone compared to patients who received $\mathrm{H}_{1} \mathrm{AT}$ and DEX (any grade $=25.6 \% \mathrm{vs}$. $9.6 \%$; grade $3 / 4=4.7 \%$ vs. $1.0 \%$, respectively). Data from the prospective and retrospective studies of panitumumab (fully humanized mAbs) and cetuximab showed that the frequency of IRRs was lower in the panitumumab group (17-19). Our findings are consistent with those of the previous reports concerning panitumumab and cetuximab, and with the hypothesis that fully humanized $\mathrm{mAbs}$ are less immunogenic than chimeric mAbs. As RAM is a fully humanized mAb, IRRs may occur at a lower rate.

In clinical practice, $d$-Chlorpheniramine maleate is a type of $\mathrm{H}_{1}$ AT commonly used to prevent the occurrence of IRRs during the administration of RAM regimens (8). The use of $d$-Chlorpheniramine maleate poses several known risks. The intake of $2 \mathrm{mg}$ of $d$-Chlorpheniramine maleate causes loss of concentration, and decreases the judgment and work efficiency to an extent comparable with drinking three glasses each containing $90 \mathrm{ml}$ of whiskey (15). An intravenous injection of $5 \mathrm{mg}$ of $d$-Chlorpheniramine maleate occupies $87 \%$ of the averaged values of available histamine $\mathrm{H} 1$ receptors in the frontal cortex. In addition, impaired performance of the central nervous system is significantly correlated with the concentration of plasma chlorpheniramine 
Table IV. Incidence of adverse events for ramucirumab.

\begin{tabular}{lcccccc}
\hline & NC/NA & Grade 1 & Grade 2 & Grade 3 & Grade 4 & All \\
\hline Proteinuria & 39 & $10(17.2 \%)$ & $5(8.6 \%)$ & $4(6.9 \%)$ & 0 & $19(32.8 \%)$ \\
Hypertension & 50 & 0 & $7(12.0 \%)$ & $1(1.7 \%)$ & 0 & $8(13.8 \%)$ \\
GI perforation & 58 & 0 & 0 & $1(1.7 \%)$ & 0 & 0 \\
Bleeding & 57 & 0 & 0 & 0 & $1(1.7 \%)$ & $1(1.7 \%)$ \\
Pneumonia & 57 & 0 & 0 & $1.7 \%)$ \\
\hline
\end{tabular}

NC/NA: No change from baseline/no adverse event; GI: gastrointestinal.

(20). These results suggest that due to the adverse side effects of $\mathrm{H}_{1} \mathrm{AT}$ premedication, which include drowsiness and dizziness, it may be advisable to restrict its use in the elderly and those who need to drive.

Our results did not reveal a clear benefit of premedication with $\mathrm{H}_{1} \mathrm{AT}$, as IRRs were not observed with either the $\mathrm{H}_{1} \mathrm{AT}$ free RAM monotherapy or the combination therapy regimens. To the best of our knowledge, this is the first report demonstrating the safety of RAM infusion without $\mathrm{H}_{1} \mathrm{AT}$ premedication, suggesting $\mathrm{H}_{1}$ AT-free RAM-containing therapies may be safe in terms of IRRs development. However, our study has some limitations. First, this was a single-center population and a retrospective nonrandomized study with a small sample size. The RAM regimen was selected according to the physician's choice, which may have introduced a selection bias. Second, data on the pharmacokinetics of RAM were not obtained. Third, our study included patients with different treatment regimens, resulting in differences in terms of premedication. Fourth, our study did not include patients with hepatocellular carcinoma who have been reported to have more IRRs in $\operatorname{RAM}(13,14)$. Finally, patients with allergic diseases could have been excluded.

The $\mathrm{H}_{1}$ AT-free RAM regimens may be considered as a treatment option for the patients with cancer who risk developing $\mathrm{H}_{1}$ AT-related side effects. Given that this was a retrospective analysis, caution must be exercised in the interpretation of these data, which require a formal confirmation in a prospective study.

\section{Conflicts of Interest}

MG: Eli Lilly, TAIHO Pharmaceutical Co., LTD., Daiichi Sankyo, Yakult Honsha Co., LTD., CHUGAI PHARMACEUTICAL CO., LTD., ONO PHARMACEUTICAL CO., LTD., Eisai, NIPPON KAYAKU, MSD, Sumitomo Dainippon Pharma Co., AstraZeneca, outside the submitted work. All other Authors have declared no conflicts of interest regarding this study.

\section{Authors' Contributions}

MY initiated this project. EG, TY, NH, MG, MN, KU, and YR designed the study protocol and wrote the manuscript. EG, $\mathrm{NH}$ and TY collected clinical information and performed statistical analysis.
Table V. Comparison of infusion-related reactions rates between our study and previous prospective trials.

\begin{tabular}{lcccc}
\hline Trial & $\mathrm{N}$ & All Grades & Grade 3 & Grade 4 \\
\hline RAINBOW (10) & 327 & $19(5.8 \%)$ & $2(0.6 \%)$ & 0 \\
REGARD (11) & 236 & $1(0.4 \%)$ & 0 & 0 \\
RAISE (9) & 529 & $31(5.9 \%)$ & $4(0.8 \%)$ & 0 \\
REVEL (12) & 627 & $23(3.7 \%)$ & $2(0.3 \%)$ & $3(0.5 \%)$ \\
REACH (13) & 277 & $17(6.1 \%)$ & $3(1.0 \%)$ & 0 \\
REACH-2 (14) & 197 & $13(6.6 \%)$ & 0 & 0 \\
Our study & 58 & 0 & 0 & 0 \\
\hline
\end{tabular}

\section{Acknowledgements}

The Authors would like to express their sincere thanks to all patients and investigators.

\section{References}

1 Rombouts MD, Swart E, Van Den Eertwegh AJM and Crul M: Systematic review on infusion reactions to and infusion rate of monoclonal antibodies used in cancer treatment. Anticancer Res 40(3): 1201-1218, 2020. PMID: 32132017. DOI: 10.21873/ anticanres. 14062

2 Van Cutsem E, Peeters M, Siena S, Humblet Y, Hendlisz A, Neyns B, Canon JL, Van Laethem JL, Maurel J, Richardson G, Wolf $M$ and Amado RG: Open-label phase III trial of panitumumab plus best supportive care compared with best supportive care alone in patients with chemotherapy-refractory metastatic colorectal cancer. J Clin Oncol 25(13): 1658-1664, 2007. PMID: 17470858. DOI: 10.1200/JCO.2006.08.1620

3 Jonker DJ, O'Callaghan CJ, Karapetis CS, Zalcberg JR, Tu D, Au HJ, Berry SR, Krahn M, Price T, Simes RJ, Tebbutt NC, van Hazel G, Wierzbicki R, Langer C and Moore MJ: Cetuximab for the treatment of colorectal cancer. N Engl J Med 357(20): 2040-2048, 2007. PMID: 18003960. DOI: 10.1056/ NEJMoa071834

4 Chung $\mathrm{CH}$ : Managing premedications and the risk for reactions to infusional monoclonal antibody therapy. The Oncologist 13(6): 725-732, 2008. PMID: 18586928. DOI: 10.1634/ theoncologist.2008-0012

5 Roselló S, Blasco I, García Fabregat L, Cervantes A, Jordan K and ESMO Guidelines Committee: Management of infusion reactions to systemic anticancer therapy: ESMO Clinical 
Practice Guidelines. Ann Oncol 28(suppl 4): iv100-iv118, 2017. PMID: 28881914. DOI: 10.1093/annonc/mdx216

6 Breslin S: Cytokine-release syndrome: overview and nursing implications. Clin J Oncol Nurs 11(1Suppl): 37-42, 2007. PMID: 17471824. DOI: 10.1188/07.cjon.s1.37-42

7 Lenz HJ: Management and preparedness for infusion and hypersensitivity reactions. The Oncologist 12(5): 601-609, 2007. PMID: 17522249. DOI: 10.1634/theoncologist.12-5-601

8 Ikegawa K, Suzuki S, Nomura H, Enokida T, Yamazaki T, Okano S, Endo K, Saito S, Yamaguchi M and Tahara M: Retrospective analysis of premedication, glucocorticosteroids, and $\mathrm{H}_{1}$-antihistamines for preventing infusion reactions associated with cetuximab treatment of patients with head and neck cancer. Int Med Res 45(4): 1378-1385, 2017. PMID: 28606015. DOI: 10.1177/0300060517713531

9 Tabernero J, Yoshino T, Cohn AL, Lee Cohn A, Obermannova R, Bodoky G, Garcia-Carbonero R, Ciuleanu T, Portnoy D, Cutsem E, Grothey A, Prausová J, Garcia-Alfonso P, Yamazaki K, Clingan P, Lonardi S, Tae Kim W, Simms L, Chang S and Nasroulah F: Ramucirumab versus placebo in combination with second-line FOLFIRI in patients with metastatic colorectal carcinoma that progressed during or after first-line therapy with bevacizumab, oxaliplatin, and a fluoropyrimidine (RAISE): a randomised, double-blind, multicentre, phase 3 study. Lancet Oncol 16(5): 499-508, 2015. PMID: 25877855. DOI: 10.1016/S1470-2045(15)70127-0

10 Wilke H, Muro K, Van Cutsem E, Oh SC, Bodoky G, Shimada Y, Hironaka S, Sugimoto N, Lipatov O, Kim TY, Cunningham D, Rougier P, Komatsu Y, Ajani J, Emig M, Carlesi R, Ferry D, Chandrawansa K, Schwartz JD, Ohtsu A and RAINBOW Study Group: Ramucirumab plus paclitaxel versus placebo plus paclitaxel in patients with previously treated advanced gastric or gastro-oesophageal junction adenocarcinoma (RAINBOW): a double-blind, randomised phase 3 trial. Lancet Oncol 15(11): 1224-1235, 2014. PMID: 25240821. DOI: 10.1016/S14702045(14)70420-6

11 Fuchs CS, Tomasek J, Yong CJ, Dumitru F, Passalacqua R, Goswami C, Safran H, Dos Santos LV, Aprile G, Ferry DR, Melichar B, Tehfe M, Topuzov E, Zalcberg JR, Chau I, Campbell W, Sivanandan C, Pikiel J, Koshiji M, Hsu Y, Liepa AM, Gao L, Schwartz JD and Tabernero J: Ramucirumab monotherapy for previously treated advanced gastric or gastrooesophageal junction adenocarcinoma (REGARD): an international, randomised, multicentre, placebo-controlled, phase 3 trial. Lancet 383(9911): 31-39, 2014. PMID: 24094768. DOI: 10.1016/s0140-6736(13)61719-5

12 Garon EB, Ciuleanu TE, Arrieta O, Prabhash K, Syrigos KN, Goksel T, Park K, Gorbunova V, Kowalyszyn RD, Pikiel J, Czyzewicz G, Orlov SV, Lewanski CR, Thomas M, Bidoli P, Dakhil S, Gans S, Kim JH, Grigorescu A, Karaseva N, Reck M, Cappuzzo F, Alexandris E, Sashegyi A, Yuraso S and Perol M: Ramucirumab plus docetaxel versus placebo plus docetaxel for second-line treatment of stage IV non-small-cell lung cancer after disease progression on platinum-based therapy (REVEL): a multicentre, double-blind, randomised phase 3 trial. Lancet 384(9944): 665-673, 2014. PMID: 24933332. DOI: 10.1016/ S0140-6736(14)60845-X

13 Zhu AX, Park JO, Ryoo BY, Yen C.J, Poon R, Pastorelli D, Blanc JF, Chung HC, Baron AD, Pfiffer TE, Okusaka T, Kubackova K, Trojan J, Sastre J, Chau I, Chang SC, Abada PB,
Yang L, Schwartz JD and Kudo M: Ramucirumab versus placebo as second-line treatment in patients with advanced hepatocellular carcinoma following first-line therapy with sorafenib $(\mathrm{REACH})$ : a randomised, double-blind, multicentre, phase 3 trial. Lancet Oncol 16: 859-870, 2015. PMID: 26095784. DOI: 10.1016/S1470-2045(15)00050-9

14 Zhu AX, Kang YK, Yen CJ, Finn RS, Galle PR, Llovet JM, Assenat E, Brandi G, Pracht M, Lim HY, Rau KM, Motomura K, Ohno I, Merle P, Daniele B, Shin DB, Gerken G, Borg C, Hiriart JB, Okusaka T, Morimoto M, Hsu Y, Abada PB and Kudo M: Ramucirumab after sorafenib in patients with advanced hepatocellular carcinoma and increased $\alpha$-fetoprotein concentrations (REACH-2): a randomised, double-blind, placebo-controlled, phase 3 trial. Lancet Oncol 20(2): 282-296, 2019. PMID: 30665869. DOI: 10.1016/S1470-2045(18)30937-9

15 Tagawa M, Kano M, Okamura N, Higuchi M, Matsuda M, Mizuki Y, Arai H, Fujii T, Komemushi S, Itoh M, Sasaki H, Watanabe $\mathrm{T}$ and Yanai K: Differential cognitive effects of ebastine and (+)-chlorpheniramine in healthy subjects: correlation between cognitive impairment and plasma drug concentration. Br J Clin Pharmacol 53(3): 296-304, 2002. PMID: 11874393. DOI: 10.1046/j.0306-5251.2001.01183.x

16 Wilke H, Glynne-Jones R, Thaler J, Adenis A, Preusser P, Aguilar EA, Aapro MS, Esser R, Loos AH and Siena S: Cetuximab plus irinotecan in heavily pretreated metastatic colorectal cancer progressing on irinotecan: MABEL Study. J Clin Oncol 26(33): 5335-5343, 2008. PMID: 18854570. DOI: $10.1200 / J C O .2008 .16 .3758$

17 Siena S, Glynne-Jones R, Adenis A, Thaler J, Preusser P, Aguilar EA, Aapro MS, Loos AH, Esser R and Wilke H: Reduced incidence of infusion-related reactions in metastatic colorectal cancer during treatment with cetuximab plus irinotecan with combined corticosteroid and antihistamine premedication. Cancer 116(7): 1827-1837, 2010. PMID: 20143444. DOI: 10.1002/cncr.24945

18 Price TJ, Peeters M, Kim TW, Li J, Cascinu S, Ruff P, Suresh AS, Thomas A, Tjulandin S, Zhang K, Murugappan S and Sidhu $\mathrm{R}$ : Panitumumab versus cetuximab in patients with chemotherapy-refractory wild-type KRAS Exon 2 Metastatic Colorectal Cancer (ASPECCT): a randomised, multicentre, openlabel, non-inferiority phase 3 study. Lancet Oncol 15(6): 569-579, 2014. PMID: 24739896. DOI: 10.1016/S1470-2045(14)70118-4

19 Yamaguchi T, Iwasa S, Nagashima K, Nagashima K, Ikezawa N, Hamaguchi T, Shoji H, Honma Y, Takashima A, Okita N, Kato K, Yamada Y and Shimada Y: Comparison of panitumumab plus irinotecan and cetuximab plus irinotecan for KRAS wild-type metastatic colorectal cancer. Anticancer Res 36(7): 3531-3536, 2016. PMID: 27354619.

20 Yanai $\mathrm{K}$ and Tashiro M: The physiological and pathophysiological roles of neuronal histamine: an insight from human positron emission tomography studies. Pharmacol Ther 113(1): 1-15, 2007. PMID: 16890992. DOI: 10.1016/j.pharmthera.2006. 06.008

Received July 27, 2020

Revised August 13, 2020

Accepted August 23, 2020 